\title{
El venezolano Francisco de Miranda ¿Iniciado masón después de muerto?
}

\section{Venezuela's Francisco de Miranda, initiated Freemason after his Death?}

\author{
José Gregorio Parada Ramírez \\ Universidad Muskingum, Ohio, Estados Unidos \\ jgregorioparada@gmail.com
}

Recepción: 25 de agosto de 2019/Aceptación: 13 de octubre de 2019

doi: https://doi.org/10.15517/rehmlac.v11i2.38475

\section{Palabras clave}

Miranda; Bonaparte; Francmasonería; revolución; independencia.

\section{Key words}

Miranda, Bonaparte, Freemasonry, Revolution, Independence.

\section{Resumen}

Mucha tinta se ha gastado para intentar abrir puentes entre la Francmasonería y el Precursor de la independencia venezolana, Francisco de Miranda. Estas líneas comienzan en Francia con un encuentro de dos grandes hombres: Miranda y Bonaparte. Ambos tienen algo en común aparte de su gran genio militar: se les suele encasillar dentro de las filas masónicas sin que haya suficientes pruebas para sustentarlo. En este artículo intentamos dar una mirada a los nexos de don Francisco de Miranda con miembros de esta hermandad, sin que por esto se le deba incluir en la lista de la afamada hermandad.

\begin{abstract}
Much has been said when creating connections between Freemasonry and the Precursor of Venezuela's independence Francisco de Miranda. The story begins in France with a very special encounter between two great men: Miranda and Bonaparte. Both have something in common besides their great military genius: they are usually classified into the Masonic ranks without enough evidence to support such a claim. In this article we try to review all possible connections between Francisco de Miranda and members of this brotherhood, a fact that is not determinant for him to be included among the members of the famous brotherhood.
\end{abstract}




\section{Encuentro de celebridades. A manera de introducción}

A nuestro juicio, uno de los trabajos más exhaustivos que jamás se haya realizado sobre el general Francisco de Miranda pertenece a Caracciolo Parra Pérez. A nuestras manos llegó una edición realizada por la Fundación Bancaribe en 1989 de tan encomiable trabajo titulado Miranda et la Révolution française. Acabado como estaba, el autor lo envía y dedica al general Juan Vicente Gómez desde Berna en 1924.

Creímos interesante abrir este trabajo sobre un tema controversial como lo es la supuesta filiación masónica del general Miranda, con un dato curioso que extrajimos del antes citado libro: El encuentro del eximio prócer y precursor de la independencia hispanoamericana con la no menos connotada figura política y militar francesa, representada por Napoleón Bonaparte. El capítulo IX está dedicado a los encuentros entre ambas figuras políticas y militares. El primero de ellos tuvo lugar en 1795, esto según el testimonio que el propio Miranda hace al general Serviez en Caracas en 1812, en el barrio Chaussée d'Antin, en el Distrito IX de París, en casa de la cortesana Julie Talma. Julie Carreau es la primera esposa del trágico François Joseph Talma que actúa en la Comedia francesa bajo la protección del pintor Jacques Louis David, líder revolucionario e instaurador del "Estilo Imperio" bajo Napoleón. Su casa era sitio de encuentro para gente ligada a ciertos medios, pero la anfitriona era ampliamente criticada por la prensa realista y maratista. Miranda tiene para entonces 45 años y es comandante en jefe del ejército francés. Napoleón tiene 26 y su fama está por llegar. Habiéndose enterado Napoleón que Miranda era un general americano le hizo innombrables preguntas a las que Miranda respondió “con la debida educación”.

Pero Napoleón habría de dar otra versión de los hechos sucedidos en casa de Mme. Laure Permon, duquesa de Abrantès:

F’ai dîné, hier, chez un homme qui est singuilier ; je le crois espion de la court d'Espagne et de l'Angleterre tout à la fois. Il loge à un troisième étage et il est meublé comme un satrape ; il crie misère au milieu de cela et puis donne des dîners faits par Méot et servis dans de la vaissele plate ; c'est une bizarre chose que je veux éclaircir'.

Después de esto, Napoleón agrega una comparación interesante, aunque inapropiada, sobre el general venezolano: "J'ai là avec des hommes de la plus grande importance ; il y en un a un, entre autres que je veux revoir : c'est un Don Quichotte, avec cette différence que celui-ci n'est pas fou”. Y cuando Mme. Permon preguntó por el nombre, Napoleón respondió enseguida que se trataba del general Miranda, "un hombre con fuego en el alma”. Justo después, Bonaparte partió y Salicetti tomó la palabra y dijo que en efecto Napoleón tenía razón y que el hombre al que se refería él lo creía mejicano, sin estar seguro. Lo adjetiva de “pícaro” y agrega que es el más sutil de toda España.

$1 \quad$ Caracciolo Parra Pérez, Miranda et la Révolution française (Caracas : Ed. Banco del Caribe, 1989), 322. "Cené ayer en casa de un hombre singular: Creo que es espía de la corte española y de la inglesa al mismo tiempo. Vive en un tercer piso en un apartamento amueblado como un sátrapa. Dice vivir en la miseria pero ofrece cenas preparadas por Méot que son servidas en vajilla llana. Es algo extraño que quiero aclarar" [mi traducción].

2 Parra Pérez, Miranda et la Révolution française, 323. "Cené con hombres de la más grande importancia. Entre ellos hay algunos que quiero volver a ver. Es un don Quijote, con la diferencia que este último no está loco" [mi traducción]. 
Sin importar cuál de las dos versiones sea la correcta, los dos generales habrían de volverse a encontrar en casa de Mme. Permon, invitados probablemente por Mr. Emilhaud que decía conocer a Miranda. Al parecer Mme. Permon al oír hablar de Miranda expresó vivos deseos de conocerlo y Mr. Emilhaud dijo que se lo presentaría y agregó que el general soñaba con darle la libertad al mundo entero. Dos días después se conocieron y Mme. Permon diría luego que Miranda tenía un toque más de originalidad que de belleza.

En casa de la citada dama, Miranda oyó a Napoleón hablar de su odio contra Inglaterra. Se pusieron de acuerdo para una cena en la Residencia Mirabeau de la rue Mont Blanc, donde vivía Miranda. No queda claro, sin embargo, que el general Miranda tuviera una o dos residencias. Lo cierto es que Bonaparte queda estupefacto por el lujo con el que vive Miranda. Según Bonaparte, el apartamento de Miranda es de ensueño, situado detrás de los jardines de Tuileries. "Il possède la plus exquise petite bibliothèque et un appartement installé avec un goût que je n'ai jamais vu de meilleur: on pourrait se croire à Athènes, à la maison de Périclès”, dice Bonaparte.

Después de estos encuentros de 1795, ambos hombres no volvieron probablemente a cruzar sus caminos.

\section{Tabla 1}

Resultados para la entrada "Napoleón Bonaparte masón” vs. similar búsqueda respecto a Francisco de Miranda

\begin{tabular}{l|c|c} 
IDIOMA & $\begin{array}{c}\text { NAPOLEÓN } \\
\text { BONAPARTE MASÓN }\end{array}$ & $\begin{array}{c}\text { FRANCISCO } \\
\text { DE MIRANDA MASÓN }\end{array}$ \\
\hline Español & 372.000 & 395.000 \\
Inglés & 90.400 & 164.000 \\
Francés & 22.400 & 5.870
\end{tabular}

\section{Unas líneas sobre Bonaparte y la francmasonería}

Cabe preguntarse a este punto a qué viene esta posible innecesaria referencia a Napoleón Bonaparte. Pues veamos:

Tal como se muestra en la tabla 1, cuando indagamos en Internet, el motor de búsqueda de Google propone 372.0oo resultados en español para la entrada "Napoleón Bonaparte masón” que contrastan con los 90.400 en inglés o los 22.400 en francés. De igual manera los resultados para similar búsqueda respecto a Francisco de Miranda son los siguientes: 395.00o en español, 164.00o en inglés y 5.870 en francés. Parece que los más discretos al respecto son los franceses y los más desbordantes en lo improbable, los hispanohablantes,

3 Parra Pérez, Miranda et la Révolution française, 325. "Cuenta con una pequeña pero exquisita biblioteca en un apartamento con gustos de los que yo no he visto mejores. Se creería uno en Atenas, en la casa de Pericles” [mi traducción]. 
en una cuestión que no admite dudas al menos hasta el sol de hoy. Ni Napoleón Bonaparte ni Francisco de Miranda, salvo que se pruebe lo contrario, fueron francmasones. La única manera de demostrar de forma tangible la pertenencia a la masonería es la presentación del diploma de masón o documentos probatorios de iniciación o asistencia a tenidas en las logias que para el caso de Napoleón y de Miranda son inexistentes. Tampoco vemos el interés que tendrían las logias implicadas en la iniciación de estas connotadas figuras de mantener en secreto su pertenencia.

Antes de entregarnos a nuestras consideraciones respecto a don Francisco de Miranda, daremos en primer lugar una rápida mirada a los nexos de Napoleón con la masonería, empezando por las llamadas logias de regimiento. Una manera eficaz para comunicarse con los notables de los países conquistados es empleada por Napoleón I, quien se sirve de las logias de regimiento por intermedio de las cuales los masones entran en contacto con las figuras más importantes de las zonas ocupadas y transmiten a la vez la cultura y el pensamiento franceses. A pesar de las opiniones extendidas, hasta la presente no se tiene ninguna prueba en cuanto a la pertenencia del emperador a la orden masónica. Hay que reconocer, sin embargo, que la familia Bonaparte tenía fuertes lazos con la francmasonería. Su padre Charles Marie pertenecía a la logia de Ajaccio. Numerosos hijos de este último, hermanos de Napoleón, fueron iniciados: Joseph, iniciado en 1783 en la Logia de Marsella "La Parfaite Sincerité", antes de convertirse, en 1804, en el Gran Maestre del Gran Oriente de Francia. Louis Bonaparte, futuro rey de Holanda, padre de Napoleón III, es nombrado Gran Orador del Gran Oriente de Francia. Jérôme, futuro rey de Westfalia, es iniciado en la logia "La Paix" de Tolón en 1801, para convertirse luego en Gran Maestre del Gran Oriente de Westfalia. Su hijo, Jérôme Napoleón, pertenece en 1848 a la logia parisina "Les amis de la Patrie”. Pierre Napoleón, hijo de Lucien, sobrino de Napoleón, era en 1848 Oficial de Honor de la Logia parisina Saint-Lucien. Josefina pertenece a una logia parisina de adopción. En 1805, 3032 oficiales, 1458 suboficiales y 437 soldados del ejército napoleónico pertenecían a las filas de la francmasonería ${ }^{4}$. Entre los 25 mariscales del Imperio, 17 son francmasones; todos los generales que participan en la batalla de Waterloo eran masones: Wellington, Ney, Grouchy, Cambronne, Wellesley y Blücher5. El cuñado de Napoleón, el mariscal Joachim Murat, casado con su hermana Caroline y sucesor de Joseph Bonaparte como rey de Nápoles, y su hijastro, Eugène de Beauharnais, hijo del matrimonio precedente de Josefina, eran también francmasones ${ }^{6}$.

Pero hasta ahora, como ya hemos acotado, ninguna filiación directa se ha probado entre el emperador y la hermandad masónica, aunque es frecuente oír en los medios masónicos expresiones como "el hermano Bonaparte" con adjetivos que además enaltecen, de tipo "el ilustrísimo", "el venerable", etc. Las mismas fórmulas se repiten para don Francisco de Miranda en boca de historiadores nacionales y extranjeros. En historia suele ser bastante cómodo repetir lo que dicen los demás, esto con el debido respeto de quienes intentan ir a las fuentes para poner al descubierto la verdad.

\footnotetext{
4 Jean-Pierre Bayard, La spiritualité de la franc-maçonnerie (Saint-Jean de Braye : Ed. Dangles, 1982), 107ss.

5 F. Daudin, L'ABCdaire de la Franc-maçonnerie (París, Flammarion, 2003), 54. Según J. Ridley, veintidós de treinta mariscales eran francmasones.

6 J. Ridley, Los masones, la sociedad secreta más poderosa de la tierra (Buenos Aires: Byblos, 2004), 227.
} 


\section{Miranda y los francmasones}

Para 1771, el joven Miranda se convierte en un viajero empedernido y alimenta sus ideas de libertad con lecturas de filósofos pertenecientes algunos a las filas masónicas. De aquí en adelante sus vivencias serán relacionadas, sin que haya prueba alguna, con la masonería. Después de llegar a España adquirió, en 1772, el grado de capitán del batallón del Regimiento de la Infantería de la Princesa. Los defensores de la tesis masónica de Miranda dicen que al año siguiente llega a ser representante de "su logia" en el extranjero. Hasta el día de hoy no se ha presentado ni el diploma de masón ni los documentos que lo liguen a la masonería, pero hay quienes más allá de avanzar hipótesis respecto a su iniciación se lanzan en elucubraciones sin ningún asidero. Se achaca a los enciclopedistas Denis Diderot y a D'Alembert las posibles relaciones para que el ilustre americano fuera iniciado. ¿Pruebas? No las hay. ¿Dónde fue iniciado? Tampoco se sabe. De saberse, sería todo un orgullo para los miembros de alguna logia francesa, estadounidense, española, venezolana o inglesa revelar que en su seno fue iniciado este gran hombre. Algunos creen que fue el mariscal Lafayette quien captó las grandes virtudes de Miranda que lo hacían candidato ideal para las filas masónicas y que lo habría apadrinado en una logia de Filadelfia. En este sentido, muchos repiten incluso en actos oficiales frases comprometedoras de este tenor: "Al parecer, Miranda recibe la luz en la logia de Filadelfia en 1783 apadrinado por el general francés Marco José Lafayette (sic.), gran maestro. La condición de aprendiz la obtiene en Londres y de gran maestro en Francia” (en el discurso pronunciado en el acto especial del natalicio de don Francisco de Miranda el 28 de marzo de 2016, día de la masonería en Venezuela) ${ }^{7}$. Ha de entenderse que la logia de Filadelfia no ha dado razón de la filiación, así como las respectivas anónimas de Inglaterra y Francia. Pero aquí hay incluso planteamientos contrapuestos, para usar las palabras de Wilfredo Padrón Iglesias, ya que no hay consenso sobre el lugar y la fecha de la iniciación ${ }^{8}$. Para unos cuantos, el acto tuvo lugar en Madrid, otros piensan que se realizó en Gibraltar y, finalmente, hay quienes creen que el hecho tuvo lugar en los Estados Unidos de América, en Filadelfia, como ya se dijo. Con todo, si ha habido alguna iniciación masónica de Miranda esta tuvo lugar en Venezuela en las circunstancias más insólitas y en un momento que parece ser bastante tirado de los pelos. Pero dejemos de momento suspendida tal cuestión que abordaremos más adelante.

Este panorama repleto de imprecisiones no puede ser sostenido evidentemente sin el apoyo documental, pero los defensores de la tesis buscan pruebas en otros filones. Por ejemplo, relacionan con permanencia el legado del Precursor con la filosofía masónica, especialmente el derecho a la autonomía de los pueblos, la separación del poder de la Iglesia y del Estado y la libertad de conciencia religiosa. La masonería mundial afirma su permanente idea de libertad de conciencia, de deshacerse de yugos opresores, idea que albergó siempre don Francisco de Miranda. El carácter de Miranda, amante de la libertad, lejano de todo dogma y fanatismo, se asocia fácilmente con el del espíritu francmasón.

Revísese el sitio Web: http://jmc-177.org.ve/la-gloria-de-miranda/

Wilfredo Padrón Iglesias. "La masonería, un punto sombrío en la trayectoria de Francisco de Miranda", Revista

de Estudios Latinoamericanos 61, no. 2 (2015): 13-30, http://www.revistadeestlat.unam.mx/index.php/latino/article/ view/52805/48798 
Navegando en fantasías, hay incluso quienes señalan que después de su iniciación...

ningún movimiento que haya hecho el Ilustre y Poderoso Hermano Francisco de Miranda por el mundo, siempre lo hizo con el previo consentimiento de los talleres francmasónicos a los cuales perteneció, rindiéndoles cuentas de todas sus labores realizadas en sus constantes viajes y visita; tanto en Europa como en América y El Caribe ${ }^{9}$.

Historiadores como Cesáreo González Navedo le otorgan el título de “Gran Maestro” y lo pone a la cabeza de filiales del "Gran Oriente". De igual modo lo hace responsable de haber constituido el Gran Oriente de la Masonería americana y de haber fundado una gran Logia Lautaro en Cádiz, logia que según el historiador se extendería por toda Hispanoamérica ${ }^{10}$. Como veremos más adelante, todo se pierde en la suposición y se difumina en la especulación. A este respecto, es bastante frecuente leer que O'Higgins contó a Miranda la leyenda de "Lautaro", el jefe indígena de los araucanos que logró reconquistar su territorio y dio la libertad a su pueblo. Muy alegremente se responsabiliza a Miranda, con harta frecuencia, como fundador de la logia Lautaro en Londres en 1797, en homenaje al héroe chileno que entregó su vida por liberar a su pueblo, logia que sería conocida como la Gran Reunión Americana o Logia de los Caballeros Racionales y que tendría filiales en Cádiz y en algunas ciudades americanas ${ }^{11}$. Don Mariano Picón Salas, antes de hablar de este encuentro, muestra la polifacética carrera del Precursor que se abre campo entre los notables de su época, lamentablemente sin precisar datos:

Con la misma vitalidad fáustica entra al salón cortesano y teje sus inagotables aventuras aristocráticas o participa en una discusión de "espiritus fuertes" que analizan la superstición y el fondo común de impostura que el volterianismo del siglo XVIII atribuía a todas las religiones ${ }^{12}$.

Luego, haciéndose eco también del encuentro de Miranda con O’Higgins agrega, sin mucho sustento, que el Precursor “inicia a un joven americano como O'Higgins en la penumbra de una logia masónica o visita un burdel italiano y lo describe en su Diario con los rasgos más plebeyos y materialistas" ${ }^{13}$. Poco más adelante, Picón Salas nos habla del supuesto gusto de Miranda por las sociedades iniciáticas: "Une en la contradicción típica de su siglo el materialismo más despiadado con aquel gusto por el misterio, por el "lado nocturno de la naturaleza humana" que animó las sociedades secretas, los cultos iniciáticos, el mesmerismo y la frenología" ${ }^{14}$.

Después de revisar detenidamente la biografía escrita por don Mariano Picón Salas

9 Citado en http://www.monografias.com/trabajos90/ilustre-poderoso-miranda-rodriguez/ilustre-poderoso-miranda-rodriguez2. $\underline{\text { shtml\#ixzz4DZJNzJFM }}$

10 Cesáreo González Navedo, "Fundación e independencia de la masonería americana", Cuadernos de Cultura Masónica (1943): 5.

11 A este respecto ver José Antonio Ferrer Benimeli, "Aproximación a la historiografía de la masonería latinoamericana”, REHMLAC 4, no. 1 (mayo -noviembre 2012): 9, https://revistas.ucr.ac.cr/index.php/rehmlac/article/ view/12144/11419

12 Mariano Picón Salas, "Miranda", Colección Clásicos merideños (Mérida: INMUCU, Alcaldía del Municipio Libertador, 2006$), 12$.

13 Picón S., "Miranda", 12.

14 Picón S., "Miranda", 13. 
y otros textos y artículos referentes a Miranda, hemos extraído los nombres de alrededor de 150 personas que de alguna manera tuvieron que ver directa o indirectamente con el Precursor de la Independencia hispanoamericana a fin de poder establecer, con mayor precisión, las amplias relaciones públicas del prócer independentista con personajes de conocida importancia histórica o determinantes en su época. Hemos filtrado aquellos cuya afiliación a la masonería ha sido probada. En otros casos, de no tener certeza, hemos señalado lo que la tradición dice respecto a su cercanía a la francmasonería sin pretender ser exhaustivos al respecto. No obligatoriamente debemos hacer caso al dicho que dice "dime con quién andas y te diré quién eres". No todos los amigos de Miranda eran masones, pero hemos de admitir que unos cuantos nombres de entre sus "contactos" aparecen en las listas de los hijos de la viuda. Helos aquí en detalle:

Durante su estadía en las Antillas (1780-1783), en su visita a Jamaica, Miranda lleva una carta de recomendación de Juan Manuel Cajigal al Almirante Sir Peter Parker que para el momento funge de Gran Maestro Provincial de la Gran Logia de Jamaica' ${ }^{15}$.

En los Estados Unidos, la lista la encabeza sin duda alguna George Washington, a quien Miranda frecuentó durante su estadía en Filadelfia. Washington regresaba de la guerra y los encuentros entre ambos fueron frecuentes a partir de diciembre de 1784 . Como bien se sabe, Washington, uno de los más afamados masones, había sido iniciado en 1752 en la logia Fredericksburg y en 1788 fue nombrado Venerable Maestre de la logia de Alexandría. Muy conocida es la postura de la primera piedra del Capitolio de los Estados Unidos por parte de Washington portando la indumentaria masónica. Henry Knox, secretario de Guerra durante el gobierno de Washington (1789-1798), es gran amigo de Miranda y masón. Ambos mantendrán fluida correspondencia. Knox señala a Miranda como "caballero español de carácter y gran información... con inteligencia y talento... entusiasta de la causa de la libertad... poseedor de un extenso conocimiento de los hombres y de las cosas"16. En Filadelfia, Miranda va a encontrarse con Thomas Jefferson, entonces congresista y quien, según testimonios del Dr. Guillotin, habría asistido a las reuniones de la Logia Las nueve musas de París y que habría marchado en una procesión masónica junto a los miembros de la Logia Los Hijos de la viuda No. 60 y la Logia Charlottesville No. 90 en 1817. El estudio de las 25000 cartas del expresidente norteamericano no muestra, sin embargo, ninguna referencia a la masonería, incluso si una logia en Virginia aparece con su nombre en 1801, Fefferson Lodge No. 65 y que después de su muerte las Grandes Logias del Sur de Carolina y de Luisiana celebraran funerales y procesiones en su honor. James Monroe (1758-1831), quien luego fuera el quinto presidente de los Estados Unidos y que mostró gran interés por los proyectos de Miranda, había sido iniciado en 1775 en la Williamsburg Lodge No. 6, en Virginia, a los 17 años. Monroe fue embajador de los Estados Unidos en París en los días de gloria de Miranda en Francia. Un buen amigo de Miranda fue también el francmasón Alexander Hamilton (1755-1804), economista, estadista, abogado, consejero de Washington y secretario del Tesoro bajo el mandato de este último. Ya definido su proyecto de invasión y

15 Ovidio Aguilar Meza, “En búsqueda de la verdad ¿Miranda fue masón?”, Biblioteca de autores y temas mirandinos (Los Teques: Fundación Fondo Editorial Simón Rodríguez, 2010), 56.

16 Luis Xavier Grisanti, "El Precursor Miranda y los Estados Unidos", Analítica, 22 de marzo de 2006, http://www.analitica.com/ opinion/opinion-nacional/el-precursor-miranda-y-los-estados-unidos/ 
de nuevo en los Estados Unidos, Miranda contacta a John Jacob Astor (1763-1848) con miras a adquirir armas para la expedición. Astor había hecho fortuna con el comercio de pieles de animales y con el negocio de bienes raíces, así como, más tarde, con el comercio del opio con Asia. El comerciante era francmasón y Maestro de la Holland Lodge No. 8, en la ciudad de Nueva York en 1788, más tarde sería Gran Tesorero de la Grand Lodge de Nueva York.

Durante su primera estadía en Londres, Miranda decide emprender un viaje por Europa al lado de su amigo, el coronel estadounidense William Smith, secretario del ministro en Londres y futuro presidente de los Estados Unidos, John Adams. De William Smith se dan señas masónicas de cierto peso en la obra de Ovidio Aguilar Meza titulada En búsqueda de la verdad ¿̇iranda fue masón? Smith y Miranda se acompañan hasta Viena, donde Miranda se entrevistará con un masón notable, el compositor Franz Joseph Hyden. En Cristiania, Noruega, Miranda es invitado por Bernard Anker a visitar la "casa de los masones". Anker era un masón que había inaugurado la logia San Olai en cuyo edificio vivía en la planta baja y la mencionada logia funcionó en el primer piso hasta $1811^{17}$. Hecho curioso es que en su visita a la casa del Sr. Khan en Cristiania, Miranda anota el número de activos de la orden masónica, información en cierto modo clasificada. En Gotemburgo visita la "sala de los francmasones" y en Estocolmo un orfanatorio mantenido por los hijos de la viuda. En septiembre de 1788 se reúne en Zúrich con Johann Kaspar Lavater, distinguido filósofo y teólogo protestante, masón de la Orden de la Estricta Observancia.

También en Londres Miranda se relaciona con otro norteamericano célebre: Rufus King, embajador de Estados Unidos en el Reino Unido, un convencido masón que comparte las ideas libertarias de Miranda y la del jesuita peruano Juan Pablo Vizcardo y Guzmán. Pero Londres le abrirá a Miranda también las puertas a personalidades diversas como el historiador británico Edward Emily Gibbon (1737-1794), un historiador de enorme trascendencia y autor de la Historia de la decadencia y caída del imperio romano (17761788). Gibbon, quien sucede a Oliver Goldsmith en la Royal Academy como profesor de historia antigua, es iniciado masón en 1774 en la Primera Grand Lodge of England, Logia de la Amistad No. 3. También entre sus amigos británicos está el dramaturgo y director de teatro Richard Brinsley Sheridan (1751-1816), francmasón según la Grand Lodge of Scotland. A la lista agregamos a Jeremy Bentham (1748-1832), filósofo, economista, pensador y escritor inglés. Bentham es un verdadero revolucionario para su época. Hacia 1785 escribe el primer argumento para la reforma de ley homosexual en Inglaterra. Lucha por la libertad individual y económica, la separación de la Iglesia y del Estado, la igualdad de género, el derecho al divorcio. Abogó también por la abolición de la esclavitud, de la pena de muerte y del castigo físico. Bentham fue un masón con marcada influencia de los jesuitas. Joseph Priestly (1723-1804), científico, teólogo, filósofo y teórico político con más de 150 obras publicadas, amigo de Benjamin Franklin y miembro de la Royal Society, sociedad íntimamente ligada a la francmasonería dado el hecho de que ambas sociedades pregonan ideales filosóficos y filantrópicos. Priestly aparece citado como masón en la obra Keats, Hermeticism and Secret Societies de Jennifer Wunder. Tanto Benjamin Franklin como Joseph Priestly son miembros de la llamada Sociedad Lunar. Miranda también conoce a Arthur Wellesley (1759-1852)

17 Aguilar Meza, “¿Miranda fuer masón?”, 63. 
duque de Wellington, militar, político y estadista británico, general durante las guerras napoleónicas, dos veces primer ministro del Reino Unido, quien estudia la posibilidad de formar y preparar un ejército para la invasión de América. El duque de Wellington, aunque miembro de la logia El Gran Firmamento de Londres, había sido iniciado en la logia irlandesa No. 494 Trim en Meath, el 7 de diciembre de 1790. En Londres forja Miranda amistad con el escritor, teólogo y escritor español José María Blanco White (1775-1841), que, aunque masón, terminó desencantado con la hermandad.

Conoce también en Francia al sacerdote Guillaume-Thomas Raynal (1713-1796) autor de La historia filosófica y política de los establecimientos y del comercio de los europeos en las dos Indias (1770). Raynal es ante todo un enciclopedista cuya obra es prohibida en Francia. Su posible pertenencia a la francmasonería, aún no comprobada, puede sugerirse por los lazos de amistad y parentesco con varios miembros de la logia de su natal St. Geniez d'Olt. Se cree también que las altas recomendaciones con las que llega a París le permitirán a Raynal iniciarse en la logia Les neuf soeurs, logia que brindaría gran apoyo a la revolución norteamericana. En París, Raynal tiene amistad con masones de alto calibre como Lafayette de quien será un verdadero mentor. Miranda también conoce a Jacques Pierre Brissot o Brissot de Warville (1754-1793), escritor y dirigente político francés, líder girondino durante la revolución francesa. Brissot y Miranda se conocen en 1792 y el militar venezolano contará con el apoyo inestimable de Brissot por la causa patriota. Brissot dirá de la revolución libertaria: "le destin de cette révolution dépend d'un homme, vous le connaissez, vous l'estimez, vous l'aimez: c'est Miranda"18. Es él quien lo propone como gobernador de Santo Domingo. Es Brissot el fundador de una sociedad llamada "Sociedad de los amigos de los negros" que tuvo una influencia importante en la política colonial francesa. Las memorias de Brissot no dejan ninguna duda de su pertenencia a la francmasonería, muy particularmente a una logia alemana, pero los rituales y el secreto eran cosas que no iban mucho con el carácter de Brissot por lo que el escritor se separó rápidamente de las filas masónicas. Con todo, esta inicial vinculación le abrió campo en el Círculo Social de Nicolas de Bonneville, círculo político bastante dinámico en los primeros años de la Revolución cuyo origen masónico es innegable. Otro miembro de la "Sociedad de los amigos de los Negros" y que milita en las filas masónicas es el alcalde de París Jerôme Pétion (1756-1794), a quien conoce Miranda en 1792. Durante los días difíciles de Miranda en París, el jurista, político y masón francés Jean Denis Lanjuinais (1753-1827) abogará por el general. Emmanuel Joseph Sieyès (1748-1836) se convertirá en eclesiástico, político, ensayista y académico francés, uno de los teóricos constitucionalistas más importantes de la Revolución francesa. Sieyès, según Picón Salas, escribe con Miranda un proyecto constitucional. Se le asocia a la francmasonería, especialmente a las logias Les Amis devenus Frères al oriente de Fréjus antes de la Revolución y luego, en París, a la Logia de las Nueve Hermanas, también conocida como Logia de los Filósofos y a la Logia de la rue du Coq Héron. Un americano bastante influyente en Miranda es el poeta Joel Barlow (1754-1812) a quien conoce en París y de quien toma la idea del nombre para el continente emancipado con el que sueña el militar venezolano, Colombeia. Barlow fue miembro de la logia St. fohn No. 4, al oriente de Hartford en Connecticut.

18 Parra Pérez, Miranda et la Révolution, 43. "La suerte de esta revolución depende de un hombre, ustedes lo conocen, ustedes lo estiman, ustedes lo aman: es Miranda" [mi traducción].

REHMLAC+, ISSN 1659-4223, vol. 12, no. 2, diciembre 2019 / junio 2020 
Antes de entrar a hablar de los hispanoamericanos con los que Miranda se codea, es conveniente hacer referencia a la supuesta visita que José del Pozo y Sucre y Manuel de Salas realizan a Miranda. Muchas inconsistencias hay en tal afirmación. La primera es que tal visita se lleva a cabo en Londres, en diciembre de 1797, pero el caso es que para entonces Miranda vive aún en París. Se dice que firman un documento en el que se fijan las bases políticas de un proyecto independentista. Ampliamente se ha difundido que del Pozo y Salas eran jesuitas y masones, afirmación puesta en tela de juicio en un trabajo reciente de Manuel Hernández González titulado "Francisco de Miranda y los jesuitas expulsos”" En el trabajo se demuestra la imposibilidad de tal encuentro. Por un lado, Manuel de Salas para 1797 se encontraba en su Chile natal y tal vez nunca conoció a Miranda. Por otro lado, José del Pozo ni era jesuita ni peruano, sino un amigo de infancia de Miranda, según el citado trabajo. El libro Oh masones admirables (2007) de Claudio A. Torres Chávez cita a José del Pozo y Sucre como masón y parte de la bien improbable premisa de que Miranda es el iniciador de la masonería peruana.

Otro amigo de infancia de Miranda era Manuel Gual. De todos es conocida su incansable lucha por la libertad y su intentona contra el poder español. Manuel Gual era un aficionado de la filosofía y la política y tenía cierto interés en las sociedades secretas lo que le permitió estar al tanto de las ideas revolucionarias francesas. Junto con José María España y otros, tuvo reuniones con masones españoles en la cárcel, encuentros que le permitieron una iniciación masónica. El 12 de julio de 1799 redactó una carta a Miranda, quien escribió al gobierno inglés amplias recomendaciones para brindar apoyo a la causa de Gual pero este, como sabemos, morirá asesinado un año después. Las implicaciones masónicas de Bernardo O’Higgins son ampliamente conocidas, pero desafortunadamente las referencias del origen de la masonería de la época de la independencia se focalizan en el rol que habría jugado Francisco de Miranda al fundar las logias Lautaro. El joven O’Higgins, según Picón Salas, durante su estancia en Londres le pide a Miranda que le enseñe matemáticas. Es necesario acotar, sin embargo, que el mismo O'Higgins no cita este episodio. Claro está que estas conversaciones determinarían en buena medida el pensamiento del futuro libertador chileno. De igual modo, Miranda mantiene correspondencia con el francmasón Saturnino Rodríguez Peña, importante político cuya actuación contribuyó a la independencia de las Provincias Unidas del Río de la Plata. También en Londres recibe, hacia finales de 1799, al naturalista y economista neogranadino Pedro Fermín de Vargas y Sarmiento (1762-1813?), quien después de larga estadía en Europa regresa al Caribe con ayuda de masones antes de acompañar a Miranda en la intentona independentista de Ocumare. Fermín de Vargas había encontrado asilo en Jamaica, isla donde se daban cita los refugiados políticos perseguidos por las autoridades reales españolas. Fermín de Vargas era amigo de otro prófugo francmasón, Antonio Nariño, con quien fundó la logia "El arcano sublime de la filantropía”, disfrazada de círculo literario. Hemos de recordar que Antonio Nariño y Miranda se conocen en Francia, en 1796, tal vez por la mediación del propio Fermín de Vargas. Estando en Londres, el 11 de septiembre de 1810, recibe, en el número 27 de Grafton street, la comisión integrada por Simón Bolívar, Luis López Méndez y Andrés Bello. Bolívar era masón activo, iniciado algunos años atrás en la logia San Alejandro de Escocia (el 11 de noviembre de 1805),

19 Manuel Hernández González, "Francisco de Miranda y los jesuitas expulsos", Montalbán, Revista de Humanidades y Educación 46 (2015). 311-321. 
al Oriente de París. Hay quienes afirman que tanto Bello como López Méndez fueron iniciados masones, de lo cual no existe certeza. No todas las relaciones de Miranda con Masones fueron cordiales. Tenemos como ejemplo al impulsivo sacerdote llanero Ramón Ignacio Méndez (17611839), representante al Congreso constituyente de 1811, quien tras una controversia y por no estar de acuerdo con los "métodos" de Miranda, le asesta una bofetada al general durante la sesión del 3 de julio.

Otra figura decisiva en los días de la emancipación venezolana fue el prelado y masón chileno José Cortés de Madariaga (1766-1826). Algunas versiones señalan que habría sido iniciado en España y que en Francia habría alcanzado el grado de Compañero. Fue en Londres donde ambos hombres se cruzaron por vez primera para simpatizar de una vez, muy especialmente por sus pensamientos en común. "Yo me glorié de ser americano cuando traté a este hombre" ${ }^{\circ 0}$, exclamó Madariaga 12 años más tarde cuando supo en San Carlos el nombramiento de generalísimo que había hecho a Miranda el gobierno del 19 de abril de 1810. El asiento principal de Madariaga en Europa fue la ciudad de Cádiz donde vivía en casa del banquero literato La Cruz en cuya propiedad también vivía el sacerdote y masón paraguayo Juan Pablo Fretes. Después de los acontecimientos del 19 de abril de 1810, Madariaga iría a Bogotá como Enviado de la Junta Suprema ante el Gobierno de Nueva Granada para constituir una liga en defensa de la campaña de Miranda, pero será perseguido y capturado por Monteverde, y luego remitido a España. Otro renombrado masón y allegado de Miranda es Carlos Soublette (1789-1879), militar y futuro presidente del Estado de Venezuela. Carlos Soublette sería compañero de estudios del también masón Antonio José de Sucre. Como ingeniero militar se une, en mayo de 1810, a las tropas de Francisco de Miranda donde conocerá un rápido ascenso hasta teniente coronel y edecán del propio general como primer ayudante de campo. Entre 1850 y 1855, Soublette sería Soberano Gran Comendador del Supremo Consejo Confederado del Grado 33. El 31 de julio de 1812, Miranda es hecho prisionero en La Guaira. En la aprehensión participan Bolívar, Chatillón y Mariano Montilla (1782-1851), quien sí se convertirá en masón algunos años después en la primera logia fundada en Angostura por el capitán inglés James Ambrose, en el mismo sitio donde será instalado el Congreso convocado por el Libertador. Esta logia será llamada "Concordia”. De igual forma Montilla sería venerable Maestro de la logia "La Beneficencia” de Cartagena a la que se afilió en 1822 .

\section{¿Fue en realidad masón el Precursor de la independencia americana?}

El mito del Miranda masón se cae muy especialmente con el hallazgo que hace el historiador norteamericano William Spence Robertson, quien descubre en Inglaterra los archivos de Miranda, extraviados por más de 100 años, después del apresamiento del general. Antoine Leleux, su secretario, los embarcó en un navío inglés. En Curazao permanecieron los documentos por espacio de dos años para luego ser enviados a Inglaterra donde quedaron bajo el resguardo del ministro de Guerra Lord Barthurst y de su familia

20 Weildler Guerra, "Recordando a Cortés de Madariaga", El Espectador, 4 de septiembre de 2015, https://www.elespectador. $\underline{\text { com/opinion/recordando-cortes-de-madariaga-columna-583974 }}$

REHMLAC+, ISSN 1659-4223, vol. 12, no. 2, diciembre 2019 / junio 2020 
hasta 1926. Fue entonces cuando el diplomático Caracciolo Parra Pérez hizo las gestiones para la compra y traslado a Venezuela. El Gobierno nacional ordenaría la publicación del mismo. Esto significa que antes de esa fecha las lagunas sobre las andanzas del Precursor eran enormes al menos en lo que respecta a su vida íntima, lo cual viene a redundar a favor de la hipótesis de un Miranda no masón puesto que ninguna referencia de peso fue encontrada en sus escritos muy a pesar de lo que aseveraban algunos historiadores desde principios del siglo $\mathrm{XX}^{21}$. Los trabajos del historiador venezolano Eloy Reverón ponen al descubierto muchas pistas que permiten esclarecer este controversial tema.

Interesante acotación hace Reverón en su blog sobre masonería mirandina:

El Historiador masón, Seal Coon, miembro de la logia de investigación histórica Ars 2uatour Coronati de Londres, quien escribiera un trabajo sobre Bolívar Masón, donde reproduce una copia certificada del acta de su recepción al grado de compañero, publicó otro minucioso escrito sobre Miranda donde admite no haber encontrado motivo alguno para pensar que Miranda hubiera pertenecido a la Masonería, y que eso no le restaba ningún mérito como personaje histórico, no sin hacer un comentario jocoso sobre la ingenuidad de los escritores de habla hispana quienes competían en la exaltación de sus héroes nacionales ${ }^{22}$.

Aunque no se ha hallado ningún rastro masónico del generalísimo, Reverón no descarta que Miranda haya pertenecido a alguna fraternidad militar, frecuentes en la época napoleónica. Reverón termina su artículo con una nota irónica en la que señala que si Miranda era masón es sin duda "porque casi todos los hermanos lo reconocen como tal, aunque estuviera en el oriente eterno desde hace tanto tiempo y nunca hubiera visitado una logia o asistido a tenida alguna" ${ }^{23}$.

¿De dónde nace pues el mito? La extendida idea de la pertenencia de la prominente figura de don Francisco de Miranda a la masonería debe su razón muy seguramente al origen de una sociedad política secreta cuya organización fue vinculada con las llamadas logias Lautaro y la Gran Reunión Americana, una logia de organización ideológica fundada por Miranda en 1798. Esto concuerda con lo expresado por el historiador español José Antonio Ferrer Benimeli, quien insiste en la confusión que se ha creado entre los términos sociedad secreta y sociedad patriótica o simplemente fundirlos como sociedades masónicas. Por su parte, Miranda no hace ninguna referencia en su diario respecto a las mencionadas logias Lautaro. De haber sido logias regulares de la masonería, como lo afirma Barboza de la Torre, se hubiera hecho solicitud para su creación, por ejemplo, ante la Gran Logia Unida de Inglaterra ${ }^{24}$. Sin embargo, de esto no hay constancia alguna. Si bien es cierto que el edecán Antoine Leleux fue encomendado por Miranda para organizar la Sociedad Patriótica, nos señala Reverón que "hasta aquí tenemos noticias de lo masónico como

21 Mitre, Vicuña Mackenna, Becerra y Mancin.

22 Eloy Reverón, "Iniciación de Francisco de Miranda en la Masonería", 13 de marzo de 2009, http://granlogiavzla.blogspot. com/2009/03/iniciacion-de-francisco-de-miranda-en.html

23 Reverón, "Iniciación de Francisco de Miranda en la Masonería".

24 Pedro A. Barboza de La Torre, Bolívar y la Francmasonería, Apuntaciones Históricas (Maracaibo: Gran Logia de la República de Venezuela, 1976), 4. 
motivación e inspiración de Francisco de Miranda para ordenar discretamente sus redes de conspiración” ${ }^{5}$. El destacado masonólogo pone de manifiesto que la filiación resultaría forzada y continúa exponiendo: “[...] de allí a encontrar pruebas positivas del ingreso o participación de Francisco de Miranda en la Masonería, no guarda siquiera sincronía con la creación del Rito Escocés (1802-1808) con los escasos 8 o 14 años que le quedarían de vida a Miranda entonces” ${ }^{26}$. Para Eloy Reverón la compulsiva idea de hacer de Miranda un masón nace en el siglo XX porque el tema, incluso el de los héroes verdaderamente masones, no es abordado durante el siglo XIX. Hubo al parecer, un deseo de resaltar los valores masónicos a través de la gesta libertaria latinoamericana para convertirse así la masonería "como piedra angular del republicanismo latinoamericano”, según las palabras de Wilfredo Padrón Iglesias, tesis sostenida fehacientemente por Pilar González Bernaldo y Felipe del Solar, este último masonólogo chileno que muy gentilmente nos aportó información interesante para este artículo.

¿Por qué habremos de quebrarnos la cabeza por un Miranda masón si eso no le agrega o le resta méritos al militar venezolano? A la fuerza no puede hacerse bandera con los logros personales de un héroe. Por el mismo apego a la verdad que promueve la francmasonería debería reconocerse, mientras no se tengan las pruebas fehacientes, que Francisco de Miranda no es masón y eso estaría más en consonancia con los postulados de la hermandad. Una conclusión interesante a la que llega Reverón es que los masones venezolanos le han concedido mayor peso a la presunta condición masónica de Miranda que a sus méritos personales, pero dejan de lado sus grandes dotes de estratega militar que le valieron un lugar preponderante de prócer de la guerra por independencia de los Estados Unidos, en la Revolución francesa o en la gesta emancipadora hispanoamericana.

Uno de los artículos más serios que aborda el tema de la supuesta filiación de Miranda a la masonería fue escrito por Wilfredo Padrón Iglesias de la Universidad de Pinar del Río y que se titula "La masonería, un punto sombrío en la trayectoria de Francisco de Miranda", publicado por la Revista de Estudios Latinoamericanos de la UNAM. El núcleo del artículo expone que la historiografía carece de elementos que puedan establecer una vinculación de Miranda con la masonería. Padrón Iglesias revisa las fuentes de autores que, por un lado, se han mostrado a favor de la tesis de un Miranda masón, incluyendo entre otros los nombres de Mariano Picón Salas, Josefina Rodríguez de Alonso y Mario Briceño Perozo. Por otro lado, cita a Manuel Gálvez y Caracciolo Parra Pérez, quienes niegan toda relación con la mencionada sociedad secreta. En efecto, Parra Pérez mantiene su posición al señalar: "A decir verdad, no hay documentos fidedignos que prueben que Miranda era francmasón [...]. Por mi parte, jamás he encontrado papel alguno relacionado con el asunto" ${ }^{27}$. Agrega el artículo que las temáticas abordadas en los diarios mirandinos son muy variadas, desde las más sofisticadas a las más pueriles, pero que en ningún caso se hace alusión a tenidas o encuentros masónicos, salvo las visitas a "casas de los francmasones” en Cristiania (Oslo, Noruega), Gotemburgo (Suecia) y Amberes (Bélgica). Durante su estancia en Jamaica, a fines de 1781, Miranda había comprado dos libros: Constituciones de

25 Reverón, "La masonería, Miranda, fuentes para su estudio", 21 de agosto de 2014, https://masoneriamirandina.blogspot. $\underline{\text { com } / 2014 /}$

26 Reverón, "La masonería, Miranda, fuentes para su estudio".

27 Parra-Pérez, Páginas de historia y de polémica (Caracas: Litografía del Comercio, 1943), 321.

REHMLAC+, ISSN 1659-4223, vol. 12, no. 2, diciembre 2019 / junio 2020 
la Francmasonería e Ilustraciones de la Masonería, señala con precisión Padrón Iglesias como únicas referencias a la masonería que aparecen en los diarios del prócer de la Independencia. Claro está que esto no es suficiente prueba para ligarlo de manera directa con los hermanos tres puntos. Un dato curioso agregado por el investigador cubano se refiere al hecho de que Miranda no fuera acusado por la Iglesia católica de pertenecer a la masonería. El Santo Oficio inició un proceso en su contra en la segunda década de 1770 “cuando el Tribunal de Sevilla y el Consejo de la Inquisición le acusaran por los: «[...] delitos de proposiciones, retención de libros prohibidos y pinturas obscenas ${ }{ }^{28}$. Padrón Iglesias concluye su artículo diciendo con prudencia que las pruebas puestas al descubierto no deben ser asumidas como definitorias, y sugiere se profundice en el tema en los diferentes ámbitos que hacen vida intelectual. Para Ovidio Aguilar Meza, las probabilidades de que Miranda haya sido iniciado masón son, al contrario, altas y cree que, de haber ocurrido, haya sido en Jamaica, abriendo así una nueva veta en este abanico que intenta discernir la posible cercanía de Miranda con la fraternidad masónica.

El título de nuestro trabajo no apunta sino a lo que creemos verdad mientras no se pruebe lo contrario y en esto coincidimos con la opinión de Eloy Reverón, quien ha estudiado a profundidad el tema. De hecho, en su acucioso trabajo sobre la Logia Esperanza de Caracas, el investigador revisó sus minutas, actas y correspondencia y solo consiguió el nombre de Francisco de Miranda en 1950, año en que José Tomás Uzcátegui, mediante decreto del Gran Maestro de la Gran Logia de Venezuela, pedía buscar los documentos que vinculaban a Miranda con la masonería, y convertía de facto como masón a Francisco de Miranda, 134 años después de su muerte. Hasta ahora nada, o casi nada se ha encontrado. El mismo decreto declaraba el 28 de marzo, fecha de nacimiento de Miranda, como el Día Masónico Nacional.

\section{Conclusiones}

No sin justa razón Caracciolo Parra Pérez dijo sobre Miranda: “Es el prócer de nuestra independencia sobre el cual se han escrito más mentiras, se han inventado más leyendas y se han creado más fantasías" ${ }^{29}$.

Vender a todo precio la idea de un Miranda masón es ciertamente un gesto loable pero carente de rigurosidad, al querer alimentar así un mito ocultando a la vez la verdad con fantasías o especulaciones. Hemos de entender que después de conocer la trayectoria de Miranda y habiéndose dado un giro a su imagen desde la publicación de sus diarios y su correspondencia, se le haya querido ensalzar justo cuando pasaba de ser un desdeñado y olvidado traidor a un héroe de amplísima proyección internacional.

Muy a pesar de la tradición y de lo que se repite con frecuencia en todas las esferas intelectuales, hemos de admitir que mientras no aparezcan registros escritos que demuestren su filiación, don Francisco de Miranda no puede ser catalogado como miembro de las filas masónicas. La importante lista de masones con los que tuvo estrecha relación no 
prueba tampoco su pertenencia a esta hermandad, solo nos permitiría suponer que Miranda pudo haber recibido propuestas para ingresar a la misma. Sus libros y su amplia formación revelan de igual modo que no desconoce los principios de dicha fraternidad.

\section{Bibliografía consultada}

Aguilar Meza, Ovidio. En búsqueda de la verdad ¿Miranda fue masón? Los Teques: Biblioteca de autores y temas mirandinos, Fundación Fondo Editorial Simón Rodríguez, 2010.

Barboza de la Torre, Pedro A. Bolívar y la Francmasonería, Apuntaciones Históricas. Maracaibo: Gran Logia de la República de Venezuela, 1976.

Bayard, Jean-Pierre. La spiritualité de la franc-maçonnerie. Saint-Jean de Braye : Ed. Dangles, 1982.

Daudin, Jean-Frédéric. L’ABCdaire de la Franc-maçonnerie. París : Flammarion, 2003.

Ferrer Benimeli, José Antonio. "Aproximación a la historiografía de la masonería latinoamericana", REHMLAC 4, no. 1 (mayo -noviembre 2012): 9, https://revistas.ucr. ac.cr/index.php/rehmlac/article/view/12144/11419 González Navedo, Cesáreo. Fundación e independencia de la masonería americana. La Habana: Cuadernos de Cultura Masónica, 1943.

Hernández González, Manuel. "Francisco de Miranda y los jesuitas expulsos”. Montalbán, Revista de Humanidades y Educación 46 (2015). 311-321.

Mornet, Daniel. "Les origines intellectuelles de la Révolution française, 1715-1787". Revue d'histoire de l'Église de France 21, no. 90 (1935): 86-92.

Padrón Iglesias, Wilfredo. "La masonería, un punto sombrío en la trayectoria de Francisco de Miranda”. Revista de Estudios Latinoamericanos, no. 61.

Parra-Pérez, Caracciolo. Páginas de historia y de polémica. Caracas: Litografía del Comercio, 1943.

Parra Pérez, Caracciolo. Miranda et la Révolution française. Caracas : Ed. Banco del Caribe, 1989.

Picón Salas, Mariano. Miranda. Mérida: Colección Clásicos merideños, INMUCU, Alcaldía del Municipio Libertador, 2006.

Ridley, Jasper. Los masones, la sociedad secreta más poderosa de la tierra. Buenos Aires: Byblos, 2004.

Wunder, Jennifer Keats. Hermeticism and Secret societies. Ashgate, 2008. 